\title{
A physiological control theory of food intake in the rat: Mark 1*
}

\author{
D. A. BOOTH \\ University of Birmingham, P.O. Box 363, Birmingham, England \\ and \\ F. M. TOATES \\ Institute of Physiology, Odense University, Odense, Denmark
}

\begin{abstract}
The theory that current supply of readily used energy is the primary control in feeding is embodied in a computer model of energy flows from the gut and to or from storage as fat. Values for all parameters are derived from physiological data. Meal patterns and cumulative food intakes are realistically predicted for normal and VMH-lesioned rats.
\end{abstract}

One of us has proposed that feeding is subject to a single regulatory control mechanism-inhibition by supply of readily metabolizable energy (Booth, 1972a, b). The availability of energy to the liver would be signaled to the central hunger system by a receptor sensitive to local metabolism (Russek, 19711) or by the hepatic sparing of glucose to deliver glucose and pancreatic insulin to a specialized diencephalic energy receptor (Debons, Krimsky, From, \& Cloutier, 1970; Pilcher, Jarman, \& Booth, in press). Given the known controls of intermediary metabolism, such a mechanism would explain both the long-term constancy in the ratio of lean to adipose body masses and the regulatory characteristics of mammalian feeding patterns.

We have embodied this theory into a physiological control model of feeding in the laboratory rat, in order to obtain the formal predictions that such a model can provide. Control systems analysis as applied to such a problem involves constructing a coherent mathematical description of the physiological components that make up the system. Then, if the behavior of the model as a whole departs seriously from the behavior of the real system, this is an indication either that some of the basic assumptions are incorrect or that something important has been omitted.

\section{METHOD}

A digital computer was employed to construct and test the model. The program used the method of successive addition, all variables being adjusted once per $10 \mathrm{sec}$ of real time. The block diagram of Fig. 1 illustrates the system.

The largest variation in energy supply derives from changes in absorption rate. In the model, rate of absorption of energy from the gut is subtracted from rate of energy entry to the gut by feeding, to obtain net flow rate of energy to the gut. This is then integrated with respect to time in order to give gut content of utilizable food energy. Our evidence from measurement of gut clearances is that absorption is proportional to the square root of

*Sponsored by J. D. Davis, who takes full editorial responsibility for its contents. the gut content in the rat (Booth, 1972a $\mathrm{a}^{2}$ ), as it is in man (Hopkins, 1966), and so we take the square root of the gut content and multiply this by the gain, $K$. Although $K$ is a constant at any particular point in time, it shows a circadian variation. It is considerably higher during the dark phase than during the light phase; in other words, the gut empties faster during the night than during the day. ${ }^{2}$ The program uses the $\mathrm{K}$ value appropriate to the simulated time.

The model shows a two-state feeding response system, either off or on. The on state is with a feeding rate of $1,000 \mathrm{cal}$ of utilizable energy per minute (about $0.3 \mathrm{~g}$ of chow per minute). This is an intermediate value from several results (Le Magnen \& Tallon, 1966; Kissileff, 1970). The off state is a feeding rate of zero. The supply of readily metabolizable energy is given by the sum of that derived from the gut and that supplied by net mobilization and storage of energy, primarily as lipid-the second important variation in energy flow. This also shows a circadian variation. The figures for lipolysis, a positive value in the model, and for lipogenesis, a negative value, were taken from respiration data (Le Magnen \& Devos, 1970). When the net energy supply rate falls to Value A or below, feeding goes from State off to State on, and continues in State on until the energy supply reaches Rate B. It is then switched to State off. Drinking is thought to behave in a similar way (Toates \& Oatley, 1970). In Fig. 1, we follow the path of the arrows around Block E. From measurements of gut contents at the start and end of meals and of the effects of nutrient infusions on feeding in the dark phase, 3 Value A was estimated to be about $18 \mathrm{cal} / \mathrm{min}$ and Value $\mathrm{B}$ as $60 \mathrm{cal} / \mathrm{min}$.

\section{RESULTS}

Figure 2 and Table 1 show the simulation of ad lib feeding, Part A being the intact rat. Meal sizes are 2-3 g, and the greater part of eating is done by night. In the light phase, meals tend to occur more frequently towards the end of the phase. This is the pattern observed in the adlib fed rat (Le Magnen \& Tallon, 1966; Oatley, 1971).

Part B of Fig. 2 is a simulation of the dynamic phase of the hyperphagia induced by ventromedial hypothalamic lesions. That is to say, lipid exchange is represented as net synthesis by day as well as synthesis by night. On the basis of body weight changes 


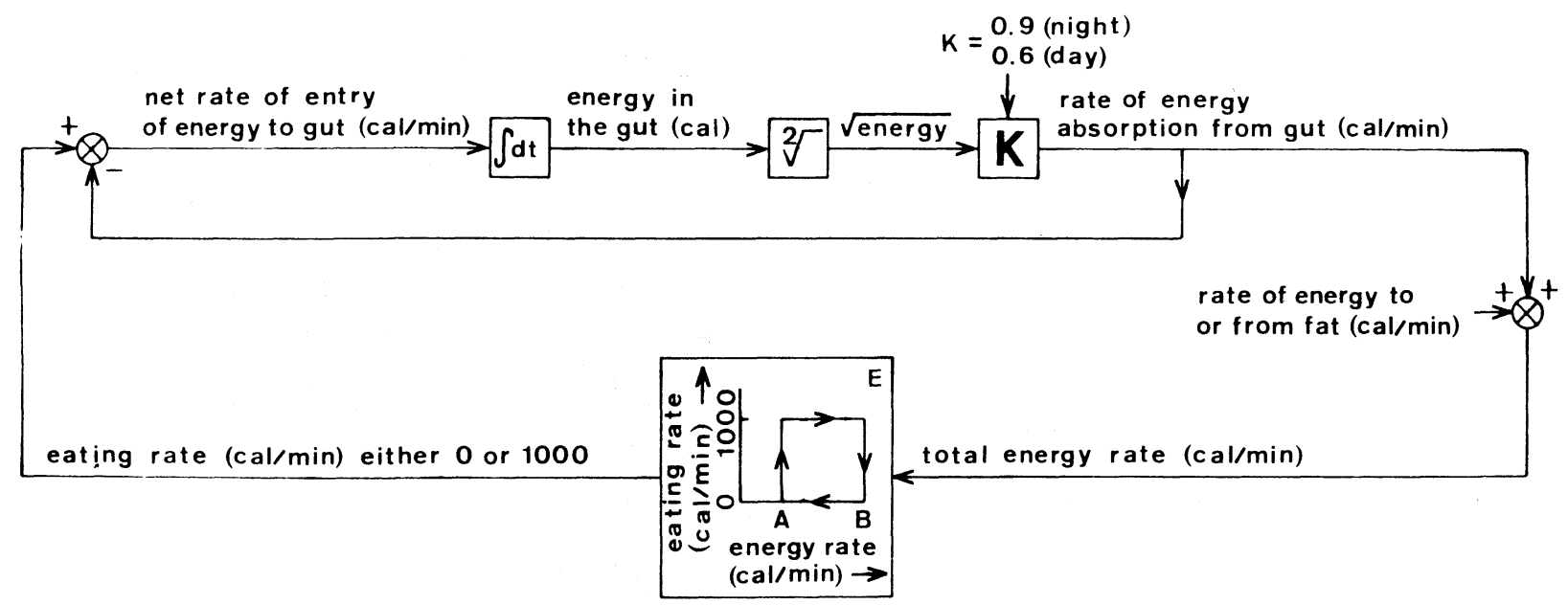

Fig. 1. Block diagram of this version of the computer model of food intake control by energy supply.


Fig. 2. Meal-pattern outputs from computer model. A, intact rat; B and C, rats with ventromedial hypothalamic lesions-B, dynamic phase, $C$, static phase. See also Table 1 .

(Kakolewski, Deaux, Christensen, \& Case, 1971) and plasma-free fatty acid concentration (Le Magnen, Devos, Gaudillière, Louis-Sylvestre, \& Tallon, 1973), synthesis appears to be the same during the day as during the night; so this information was supplied to the computer. In the model, the greatly increased food intake during the day is the consequence of the hypothalamic hyperphagic rat's taking larger meals, and this indeed is the case in the real rat (Le Magnen et al, 1973). According to the model, the reason why such a rat takes larger meals during the day than during the night is that the gut empties more slowly during the day. Since gut emptying rate is dependent upon the amount contained in the gut, it is necessary to have a large gut content in order to get the same satiating rate of glucose absorption as would be obtained with a smaller gut content during the night. As the gut content is greater, it takes longer for the gut to empty, and so meals are more widely spaced.

Figure $2 \mathrm{C}$ shows a simulation of the static phase of hyperphagia, on the assumption that net fat exchange is always zero. In the absence of a circadian adipose 
Table 1

Cumulative Food Intakes (Grams) for Light and Dark Phases in Modeled and Real Rats

\begin{tabular}{lccccc}
\hline & \multicolumn{2}{c}{ Dark } & Phase & & \multicolumn{2}{c}{ Light } & Phase \\
\cline { 2 - 3 } Type of Rat & Model & Real & & Model & Real \\
\hline A Normal & 13.0 & 17.4 & & 7.6 & 7.6 \\
$\begin{array}{l}\text { Dynamic } \\
\text { Hyperphagia }\end{array}$ & 13.0 & 17.7 & & 13.6 & 15.5 \\
$\begin{array}{l}\text { Static } \\
\text { Hyperphagia }\end{array}$ & 10.5 & 9.2 & & 7.2 & 7.9 \\
\hline
\end{tabular}

Note-The intake data for real rats are taken from Le Magnen et al (1973).

influence, the powerful effect of the circadian variation in gut emptying characteristics is made clearly evident.

\section{DISCUSSION}

Although this is a preliminary version of a model designed to account only approximately for the primary regulatory factors in food intake, it shows reasonable agreement with the behavior of the rat.

We conclude that computer simulation, because of its ability to model quantitatively the causal factors interacting to produce subtle aspects of performance and hence to suggest explanations, is an appropriate tool for the study of motivated behavior. This is particularly so as we have found intuitive insight to be quite inadequate even for accurate qualitative predictions concerning the behavior of systems of the kind discussed here. The relatively realistic output from this version of the model of the major energy flows supports the theory that the single factor of energy supply is basic to the control of feeding (Booth, 1972a, b, c; Booth \& Davis, 1973; Booth, Lovett, \& McSherry, 1972).

\section{REFERENCES}

Booth, D. A. Satiety and behavioral caloric compensation following intragastric glucose loads in the rat. Journal of Comparative \& Physiological Psychology, 1972a, 78, 485-512.

Booth, D. A. Postabsorptively induced suppression of appetite and the energostatic control of feeding. Physiology \& Behavior, 1972b, 9, 199-202.

Booth, D. A. Conditioned satiety in the rat. Journal of Comparative \& Physiological Psychology, 1972c, 81, 457-471. Booth, D. A., \& Davis, J. D. Gastrointestinal factors in the acquisition of oral sensory control of satiation. Physiology \& Behavior, 1973, 11, 23-29.

Booth, D. A., Lovett, D., \& McSherry, G. M. Postingestive modulation of the sweetness preference gradient in the rat. Journal of Comparative \& Physiological Psychology, 1972, 78, 485-512.

Campbell, C. S., \& Davis, J. D. Licking rate of rats is reduced by intraduodenal and intraportal glucose infusion. Physiology \& Behavior, 1974 , in press.

Debons, A. F., Krimsky, I., From, A., \& Cloutier, R. J. Site of action of gold thioglucose in the hypothalamic satiety center. American Journal of Physiology, 1970, 219, 1397-1402.

Hopkins, A. The pattern of gastric emptying: A new view of old results. Journal of Phy siology, 1966, 182, 144-149.

Kakolewski, J. W., Deaux, E., Christensen, J., \& Case, B. Diurnal patterns in water and foot intake and body weight changes in rats with hypothalamic lesions. American Journal of Physiology, 1971, 221, 711-718.

Kissileff, H. R. Free feeding in normal and "recovered lateral" rats monitored by a pellet detecting eatometer. Physiology \& Behavior, 1970, 5, 163-173.

LeMagnen, J., \& Devos, M. Metabolic correlates of the meal onset in the free food intake of rats. Physiology \& Behavior, $1970,5,805-814$.

Le Magnen, J., Devos, M., Gaudillière, J.-P., Louis-Sylvestre, J., \& Tallon, $\dot{S}$. Role of a lipostatic mechanism in regulation by feeding of energy balance in rats. Journal of Comparative \& Physiological Psychology, 1973, 84, 1-23.

Le Magnen, J., \& Tallon, S. La périodicité spontanée de la prise d'aliments ad libitum du rat blanc. Journal de Physiologie (Paris), 1966, 58, 323-349.

Oatley, $K$. Dissociation of the circadian drinking pattern from eating. Nature, 1971, 229, 494-496.

Pilcher, C. W. T., Jarman, S. P., \& Booth, D. A. The route of glucose to the brain from food in the mouth of the rat. Journal of Comparative \& Phsyiological Psychology, in press.

Russek, M. Hepatic receptors and the neurophysiological mechanisms controlling feeding behavior. In S. Ehrenpreis and O. C. Solnitsky (Eds.), Neurosciences research. Vol. 4. New York: Academic Press, 1971.

Toates, F. M., \& Oatley, K. Computer simulation of thirst and water balance. Medical \& Biological Engineering, 1970, 8, 71-87.

\section{NOTES}

1. The inhibitory effects of glucose and nonglucogenic metabolizable agents relative to 3-methylglucose when given in suitably small doses intraperitoneally (D. A. Booth, in preparation) indicate that the receptors stimulated by such injections are indeed metabolic, not merely chemospecific as Russek (1971) suggested.

2. Data presented to the Fifth International Conference on Regulation of Food and Water Intake, Cambridge England, 1971 (D. A. Booth and S. P. Jarman, submitted for publication).

3. C. S. Campbeil and J. D. Davis, unpublished results and in press.

(Received for publication March 13, 1974.) 